\title{
THE DUAL ROLE OF STUDENTS PURSUING A HIGHER DEGREE AND PROVIDING CARE TO THEIR CHILDREN AND FAMILY MEMBERS DURING THE COVID-19 PANDEMIC
}

\author{
Forgive Avorgbedorit, \\ Helene Vilme ${ }^{2}$ \\ ${ }^{1} \mathrm{PhD}, \mathrm{RN}$, \\ School of Nursing, \\ The University of North Carolina at Greensboro, \\ Greensboro, NC, USA \\ ${ }^{2} \mathrm{DrPH}, \mathrm{MPH}, \mathrm{MS}$, \\ Department of Population Health Sciences, \\ Duke University, School of Medicine, \\ Durham, NC, USA
}

\begin{abstract}
:
The objective of this qualitative study was to explore the psychological well-being of college students during the COVID-19 pandemic and highlight their experience as caregivers. A total of 1444 college students responded to the questionnaire on the impact of COVID-19 on their lives. Qualitative responses from 25 female and 7 male college students who serve as caregivers were analyzed. Data were assessed using thematic analyses. The analysis revealed that college students' caregiving experiences impacted every aspect of their lives, including psychological health, academic performance, and career. Students who served as caregivers indicated that the mandated "Stay-at-Home" order resulted in homeschooling children, working from home, and attending school via online at home, limiting space for work, school, childcare, and homeschool. This led to increased stress, difficulty finding childcare, a drop in GPA for some, fear of delayed graduation, and financial distress. Conclusion: University students serving as caregivers were negatively affected during the pandemic. These individuals play a significant role in the workforce; therefore, rethinking resources and policies promoting their success as they serve their loved ones is in society's best interest.
\end{abstract}

Keywords: caregivers, college students, COVID-19, pandemic

${ }^{i}$ Correspondence: email $\underline{\mathrm{f} \text { avorgbedo@uncg.edu }}$ 


\section{Introduction}

The coronavirus disease (COVID-19) pandemic disrupted normal patterns of human lives (Matvienko-Sikar et al., 2020; Wardell et al., 2020), resulting in social isolation, school closures, and increased caregiving responsibilities (Pavalko \& Woodbury, 2000; Pinquart \& Sörensen, 2003; Prime, Wade, \& Browne, 2020; Salami, Okoduwa, Chris, Ayilara, \& Okoduwa, 2021). Caregiving involves the process of helping another person to meet physical, mental, emotional, and social needs (Hermanns \& Mastel-Smith, 2012). Evidence indicates that younger adults are taking more caregiving responsibilities (Levine et al., 2005), suggesting that these caregivers could be in college pursuing higher education. Furthermore, these individuals who are potentially in college lack anticipatory guidance on the caregiving responsibilities (Baus, Dysart-Gale, \& Haven, 2005), suggesting that the caregiving roles could significantly affect their physical and mental health (Trujillo, Perrin, Elnasseh, Pierce, \& Mickens, 2016). A recent study found a significantly higher school-family conflict for working student parents compared to working students (Brauer \& Foust, 2020). Before the pandemic, Denning et al. suggest the need to study college students balancing work, family, and school (Denning, Brannan, Murphy, Losco, \& Payne, 2018) as this population is unique.

Although caregiver stress is well documented, very few studies have explored the stress of serving a dual role as a caregiver while pursuing a college degree. Therefore, the purpose of the study is to explore the impact of COVID-19 on individuals acting as caregivers while also pursuing a higher degree. Exploring the psychological wellbeing of students during the pandemic will highlight the experience of caregivers, which institutional organizations and governments can use to inform policies that strengthen the education pathway for this subset of the population that has dedicated themselves to serving others.

\section{Material and Methods}

\subsection{Study Design}

A mixed method approach was used to assess the impact of COVID-19 on college students. This manuscript explores the open-ended responses related to the impact of COVID-19 on individuals serving as caregivers while enrolled in a tertiary education program.

\subsection{Recruitment and Data Collection}

Between May and October 2020, students were recruited via university intranet systems, classroom announcements, and word of mouth using a standardized text indicating the purpose of the study, eligibility criteria, data collection procedures, and the survey link. 


\subsection{Ethical Approval and Consent}

This study was approved by Duke University and the nine collaborator's colleges and universities. Informed consent was obtained via Qualtrics before students were able to access the questionnaire.

\subsection{Data Analysis}

The coding and theme identification processes for this manuscript were guided by Braun and Clarke (2006) six steps process: 1): familiarizing with data; 2) generating initial coding; 3) Searching for themes; 4) Reviewing of themes; 5) Defining and naming of themes; 6) Reporting the findings. The co-authors, FA and HV served as the coders for this manuscript and analyzed the student's open-ended responses using NVivo. Concerning familiarization with the data, FA and HV reviewed the open-ended responses by reading the responses multiple times, jotting down initial impressions independently to reduce analysis coding bias. To generate the initial codes, FA and HV independently searched for recurring patterns to generate the initial coding across the entire data set. Once the initial coding was generated, it was subsequently refined with input from all co-authors. Afterward, FA and HV independently searched for themes by reviewing the responses of the open-ended questions searching for meaningful patterns. Following the identification of themes, FA and HV independently read the text associated with each theme, checking the themes relevance in relation to the codes extracted and across the entire data set. Ongoing analysis to refine the themes involved FA and HV meeting to identify the 'essence' of each theme by discussing how each theme fit with each other and the purpose of the study. The final step consisted of reporting the present manuscript findings by selecting compelling extracted examples of the coded text for each theme, presented below.

\section{Results}

\subsection{Sample Characteristics}

Out of the 2,035 students in the US who participated in the study, 1,444 responded to an open-ended question about students' experiences with COVID-19. A total of 32 students, including both men and women, disclosed the overall impact of COVID-19 related measures such as school closures on their academic work and increased responsibility of providing care to family and friends. The participants mean age was approximately 35 years. Table 1 shows the detailed description of the participants included in this manuscript. 
Table 1: Characterizing of college students study participants

\begin{tabular}{|c|c|}
\hline Characteristic & $n(\%)$ or $M \pm S D[M e d](\operatorname{Min}, M a x)$ \\
\hline Age (years) & $35 \pm 8.4[34.5](20,51)$ \\
\hline \multicolumn{2}{|l|}{ Gender } \\
\hline Male & $7(22)$ \\
\hline Female & $25(78)$ \\
\hline \multicolumn{2}{|l|}{ Race/Ethnicity } \\
\hline Asian & $2(6.3)$ \\
\hline Black of African American & $2(6.3)$ \\
\hline Middle Eastern & $1(3.1)$ \\
\hline Multiracial & $1(3.1)$ \\
\hline Other & $1(3.1)$ \\
\hline White & $25(78.1)$ \\
\hline \multicolumn{2}{|l|}{ Education } \\
\hline Graduate students & $22(68.8)$ \\
\hline Juniors & $1(3.1)$ \\
\hline Sophomores & $3(9.4)$ \\
\hline Seniors & $5(15.6)$ \\
\hline Other & $1(3.1)$ \\
\hline \multicolumn{2}{|l|}{ Education Classification } \\
\hline Full-time & $18(56.2)$ \\
\hline Part-time & $14(43.8)$ \\
\hline
\end{tabular}

As shown in Table 2, we identified seven themes regarding the dual role of schooling and providing care to friends and family during the pandemic, including providing care and childcare; needs and difficulty.

Table 2: Themes, Codes, and Exemplar quotations

\begin{tabular}{|l|l|l|}
\hline Themes & \multicolumn{1}{|c|}{ Codes } & \multicolumn{1}{c|}{ Exemplar quotations } \\
\hline $\begin{array}{l}\text { Psychological toll, } \\
\text { isolation as a source of } \\
\text { stressors, financial } \\
\text { distress, meeting } \\
\text { basics needs, and } \\
\text { increased } \\
\text { responsibilities. }\end{array}$ & Caretaker/caregiver & $\begin{array}{l}\text { "As a mom, this has been a difficult situation. Between } \\
\text { trying to explain things to my children, trying not to let } \\
\text { them be scared, then working full time, plus helping them } \\
\text { with their online schooling." (40, Female, Senior, } \\
\text { Midwest) }\end{array}$ \\
& & $\begin{array}{l}\text { "I am a caretaker for someone with dementia, so it has } \\
\text { been very difficult being stuck in the house for months on } \\
\text { end with someone in that constant mental state. It is hard } \\
\text { to prioritize school when your mental health is so greatly } \\
\text { impacted." (28, Female, Graduate student, Midwest) }\end{array}$ \\
\hline $\begin{array}{l}\text { Need for childcare, } \\
\text { and difficulty in } \\
\text { finding childcare }\end{array}$ & Needs childcare & $\begin{array}{l}\text { "I'm a single parent, which was not a question. Having a } \\
\text { toddler in the house without childcare impacts my ability } \\
\text { to complete my coursework and do my job } \\
\text { responsibilities." (34, Female, Graduate, South) }\end{array}$ \\
\hline & & \\
\hline
\end{tabular}




\begin{tabular}{|l|l|l|}
\hline \hline & $\begin{array}{l}\text { "I am a single mom with two young kids, so the debate } \\
\text { about them going back to school or not has been the } \\
\text { biggest stressor. Childcare is not easy to find during a } \\
\text { pandemic." (32, Female, Graduate Student) }\end{array}$ \\
& $\begin{array}{l}\text { "Having a toddler in the house without childcare impacts } \\
\text { my ability to complete my coursework and do my job } \\
\text { responsibilities." (34, Female, Graduate student, } \\
\text { South) }\end{array}$ \\
\hline & $\begin{array}{l}\text { "Difficulty with childcare so I can still work and } \\
\text { complete my classes." (42, Female, Senior, Midwest) }\end{array}$ \\
\hline
\end{tabular}

\subsection{Psychological Impacts on Students Resulting from Caregiving Roles}

The participants in this study expressed their experience pursuing higher education and being responsible for family and friends' care during the pandemic. They indicated that being a caretaker while pursuing a college degree was difficult, and some expressed that it had a psychological toll, impacting eating habits and academic performance.

"As a parent of 3 school-aged children, a full-time employee in a university research setting, and a graduate student in public health, COVID-19 has touched every part of my life. At the start of the pandemic, the whirlwind of having 3 kids in online school, then applying for rapid-response grants at work related to COVID-19, all while constantly analyzing the pandemic in my Epidemiology classes, I felt I could not escape COVID. It took a toll on me psychologically and in turn, my eating habits worsened and I drank more than a healthy amount of alcohol." (40, Female, Graduate student, Midwest)

"It has been stressful and with two children now at home full time, it is more difficult to complete school work and will likely result in my taking a decreased course load." (41, Female, Graduate student, South)

\footnotetext{
"As a single mother, who works full time, has two first graders and is taking grad school courses, it has been incredibly stressful. I managed to finish the spring semester once it transitioned to online. I struggled with whether to continue classes this fall given the challenges with having two young school age children who are also home full time virtually while I'm also trying to get my own work done. I decided to try, but it has been difficult. I worry I may need to pause classes which would delay my graduation and I fear if I lose momentum now, I may not end up re-engaging with my studies. If my university decides to go back to on-campus instruction I may also need to consider dropping classes as I am the sole parent to my kids and I have asthma and I am a caregiver for my 88 year old grandmother. I need to remain healthy. (37, Female, Graduate student, Midwest)
}

"I work in the medical field full time as well as taking college courses and trying to homeschool my 4 kids as a single parent. This has been beyond brutal and depressing. I am 
overworked, underpaid, and struggle trying to educate my kids where the system has failed them in many ways. My own grades are suffering, and I barely make it by financially." (40, Female, Other, Midwest)

"My GPA had slid from a 3.9 to a 3.6 and I handed in my first late assignment ever, this semester. I am having a hard time juggling everything" (48, Female, Graduate student, Midwest)

\subsection{Social Distancing is a Source of Stressors for Student Caregivers}

Social distancing and isolation are the hallmarks of public health measures to mitigate the rapid spread of COVID-19. The participants indicated that the public health measures, especially isolation, were the source of stressors.

"The biggest stressor has come from working from home. Everything moved to this one space- work, childcare, school." (34, female, Graduate Student, South)

"It has been stressful and with two children now at home full time." (41, Female, Graduate student, South)

\subsection{Financial Distress Concerning Meeting Basics Needs while Serving as a Caregiver and Student}

As public health measures were put in place, parents were responsible for providing care to their friends and family and bore the responsibility of keeping their families safe. Some participants described the overall effects of the pandemic on their entire lives, including the impact it had on their finances and ability to meet basic needs.

"We have been faced with many challenges. Then between my pay being cut, my husband getting laid off, we have had to turn to credit cards in order to purchase food." (40, Female, Senior, Midwest)

"My insomnia has gotten worse. I lost 15 lbs because I have lost my appetite. I don't do well in this environment, and my grades dropped. Very scary. Worried about being safe, food, jobs, and household items. COVID-19 has put a strain on my personal life and school performance. Like stated in a previous question, my children's daycare was closed so I am now home with them full time with no help." (20, Female, Sophomore, South)

\subsection{Increased Responsibilities as a Caregiver and a Student}

As the family responsibility increased, the participants' roles shifted; they embraced the caregiving role and deemed their academic work extra. The sudden change in the home setting was disruptive and added additional stress to the home. The responsibility shifts have also impacted the ability of student caregivers to complete their work and focus on their studies. 
"It has been a rough transition for me because I am the family's day-to-day caretaker, but I know others who have had it much worse. It is hard to concentrate on schoolwork and motivate myself because of my family and constant chores. I feel like school has become so much more stressful and burdensome." (20, male, Sophomore, South)

"It has been stressful. My mother and teenage daughter have become clinically depressed and anxious. My two college Junior/seniors came back to my house. I am immunecompromised and my spouse does not take COVID seriously enough. I have had trouble procuring the basic necessities at times, which is exacerbated by not being able to shop in public." (48, Female, Graduate student, Midwest)

Participants expressed needing childcare and difficulty finding childcare. The participants required childcare to focus on their academic work.

\subsection{Needs for Childcare due to School Closures}

"The strain of parenting during a pandemic while going to school, and the differential stress on mothers versus fathers. Time! My children are at home full time and managing childcare with my responsibilities is basically impossible." (41, Female, Graduate student, Midwest)

"My children's daycare was closed so I am now home with them full time with no help. They are 1 year old twins, so I have little time to study or complete my courses which reflected in my grades for the semester." (20, Female, Senior, South)

"Work and classes are difficult without childcare" (34, Female, Graduate student, South)

"I'm a stay at home parent to a toddler and infant and I typically need to get away to work, which I haven't been able to do since Covid started" (34, Female, Graduate student, Midwest)

"Work and classes are difficult without childcare. Homeschooling my children for the end of the spring semester was even more difficult, but we got through it." (34, Female, Graduate student, South)

\subsection{Difficulty Finding Childcare}

The participants disclosed their desire to obtain childcare but were met with difficulty finding childcare. Lack of childcare negatively impacted the caretakers.

"Childcare is not easy to find during a pandemic." (32, Female, Graduate student, South) 
"Difficulty with childcare so I can still work and complete my classes. Stressful."

(42, Female, senior, Midwest)

\section{Discussion}

The objective of this manuscript was to explore the impact of COVID-19 on individuals serving as caretakers/caregivers while also pursuing a higher degree. The themes that emerged were psychological toll, isolation as a source of stressors, financial distress and concern meeting basics needs, increased responsibilities, need for childcare, and difficulty in finding childcare.

Although the participants combined their caregiving role with their academic work, the pandemic exerted a psychological toll leading to worsened eating habits and academic performance. One of the unhealthy habits linked to COVID-19 is poor dietary health behaviors (Khubchandani, Kandiah, \& Saiki, 2020; Werneck et al., 2020), which is linked to overall health and wellbeing (Mattioli, Puviani, Nasi, \& Farinetti, 2020). For students who are also caregivers, physical and mental health is paramount to provide care and perform well in their studies.

As with a decline in mental health and mounting pressure from their caregiving role, the participants' academic performance was lagging, resulting in decrease GPAs. GPA plays a role in individuals furthering their educations (Hen \& Goroshit, 2014; Ibrahim \& Wah, 2020). Research indicates that level of education is not simply associated with future earnings but also with an individual's health status (Zajacova \& Lawrence, 2018). Thus, there is a need to consider the impact of the pandemic on students serving as caregivers when creating infrastructure, policies, and procedures to handle future pandemics.

One of the first public health measures and a necessary action early in the pandemic was social or physical distancing (Advice for the Public, 2020). The measures resulted in social isolation and the inability to socialize, see friends, and do activities that help cope with stress. Similar to Devaraj and Patel (2021) as well as Wang et al. (2020) findings, participants in this study were affected psychologically by the preventive measures in the US that restricted mobility early in the pandemic. Furthermore, the participants reported that isolation was a stressor for them because everything (school, work, and childcare) was designated to a single space, the home. These activities taking place in an area that was not originally designed to accommodate all these activities affected the psychological health of the caregivers during the pandemic. Research has shown that caregivers have a higher level of stress than non-caregivers (Davidson et al., 2020; Pinquart \& Sörensen, 2003) Poor psychological health has been linked to physical inactivity (Chen et al., 2020) and poor health maintenance and coping (Wardell et al., 2020). The mental wellbeing of caregivers is paramount to the well-functioning of the family unit (Prime et al., 2020) and the ability of the caregiver to meet the needs of the care recipients (Kohls, Baldofski, Moeller, Klemm, \& Rummel-Kluge, 2021). 
Furthermore, the effect of the pandemic on the caregivers resulted in financial distress and concern for meeting basic needs. The economic distress resulted from the loss of jobs by the participants or their spouse or a family member. During the earlier part of the pandemic, evidence suggested that women were more likely to lose their jobs than men (Alon, Doepke, Olmstead-Rumsey, \& Tertilt, 2020; Kabeer, Razavi, \& van der Meulen Rodgers, 2021). Moreover, some students, particularly women, had to choose caregiving over employment because schools were closed, and they had to take up their children's education (Bahn, Cohen, \& van der Meulen Rodgers, 2020; Woskie \& Wenham, 2021). As demonstrated in the results of this study, women were at the forefront of caregiving, and they were disproportionately part of the unpaid domestic work prepandemic (Revenson et al., 2016; Russell, Hutchison, Tambling, Tomkunas, \& Horton, 2020). The pandemic magnified the burden women have carried as part of day-to-day activity. Thus, the pandemic has created the opportunity for society to reflect on the role of women and provide policies and resources to reduce the burden on women, especially while they manage the dual role of students and caregivers.

Additionally, the participants also expressed their desire to find childcare during the pandemic. They reported that childcare was not easy to find and that it was an extra responsibility that impacted their academic performance. Students' caregivers may lack coping skills to deal with increased responsibilities leading to poor academic performance (Brauer \& Foust, 2020; Champlain, 2012). The pandemic has provided the rationale for society to provide community resources that can help alleviate some of the burdens students face while pursuing higher education and meeting all the demands that society imparts on them.

\subsection{Limitations}

The experience of the caregiving role presented in this paper is based on the question relating to the overall impact of COVID-19 on college students. The parent study questionnaire did not directly ask about the caregiving role as a college student, hence the responses related to this topic were limited. However, the issues relating to caregiving roles and academic work significantly impacted the participant's lives, thus, future studies need to explore the issue further.

\subsection{Recommendations}

College students should be aware that the dual role as a student and caregiver and has potential impacts on their physical and mental health. Society must provide resources for students to effectively perform both roles and maintain their mental health.

\section{Conclusions}

The caregiver burden is well documented in studies. However, the dual role of caregiving and pursuing higher education has yet to be explored fully. Students are attending school while working, providing care for their children and sometimes family members. The 
added challenges of navigating all of their responsibilities during the pandemic negatively affected all aspects of students' lives. College students are the backbone of the future workforce, and rethinking resources and policies that can promote their success is in the best interest of society.

\section{Conflict of Interest Statements}

The authors declare no conflict of interests.

\section{Funding}

This research was supported by funding from the National Heart, Lung, and Blood Institute under grant [NHLBI 5K12-HL138030-03].

\section{References}

Alon, T., Doepke, M., Olmstead-Rumsey, J., \& Tertilt, M. (2020). The Impact of COVID19 on Gender Equality. doi:10.3386/w26947

Advice for the public. (2020). World Health Organization. https://www.who.int/emergencies/diseases/novel-coronavirus-2019/advice-forpublic

Bahn, K., Cohen, J., \& Meulen Rodgers, Y. (2020). A feminist perspective on COVID-19 and the value of care work globally. Gender, Work \& Organization, 27(5), 695-699. doi:10.1111/gwao.12459

Baus, R., Dysart-Gale, D., \& Haven, P. (2005). Caregiving and Social Support: A Twentyfirst Century Challenge for College Students. Communication Quarterly, 53(2), 125142. doi:10.1080/01463370500090068

Brauer, M. C., \& Foust, M. S. (2020). Evaluating Academic and Work-Related Factors in Working Community College Students with and Without Children. Psi Chi Journal of Psychological Research, 25(3), 291-300. doi:10.24839/23257342.jn25.3.291

Champlain, K. (2012). Hidden Caregivers: A Literature Review of Young Caregivers in the United States. Doctoral dissertation, University of Pittsburgh

Chen, P., Mao, L., Nassis, G. P., Harmer, P., Ainsworth, B. E., \& Li, F. (2020). Coronavirus disease (COVID-19): The need to maintain regular physical activity while taking precautions. Journal of Sport and Health Science, 9(2), 103-104. doi:10.1016/j.jshs.2020.02.001

Cruse, L. R. (2020, July 26). Student Parents in The Covid-19 Pandemic: Heightened Need \& the Imperative for Strengthened Support. IWPR 2020. https://iwpr.org/iwprissues/student-parent-success-initiative/student-parents-in-the-covid-19pandemic-heightened-need-the-imperative-for-strengthened-support-2/

Davidson, B., Schmidt, E., Mallar, C., Mahmoud, F., Rothenberg, W., Hernandez, J., . . . Natale, R. (2020). Risk and resilience of well-being in caregivers of young children 
in response to the COVID-19 pandemic. Translational Behavioral Medicine, 11(2), 305-313. doi:10.1093/tbm/ibaa124

Devaraj, S., \& Patel, P. C. (2021). Change in psychological distress in response to changes in reduced mobility during the early 2020 COVID-19 pandemic: Evidence of modest effects from the US. Social Science $\mathcal{E}$ Medicine, 270, 113615. doi:10.1016/j.socscimed.2020.113615

Denning, E. C., Brannan, D., Murphy, L. A., Losco, J. A., \& Payne, D. N. (2018). Not All Roles Are the Same: An Examination Between Work-Family-School Satisfaction, Social Integration, and Negative Affect Among College Students. Psi Chi Journal of Psychological Research, 23(2), 166-178. doi:10.24839/2325-7342.jn23.2.166

Hen, M., \& Goroshit, M. (2014). Academic self-efficacy, emotional intelligence, GPA and academic procrastination in higher education. Eurasian Journal of Social Sciences, 2(1), $1-10$.

Hermanns, M., \& Mastel-Smith, B. (2012). Caregiving: A Qualitative Concept Analysis. Qualitative Report, 17, 75. doi:10.46743/2160-3715/2012.1727

Ibrahim, I. A., \& Wah, T. K. (2020). The Academic Self-Efficacy Among Undergraduates: The Role of Gender, CGPA and Trait Emotional Intelligence. Trends in Undergraduate Research, 3(1), e7-12. doi:10.33736/tur.1890.2020

Kabeer, N., Razavi, S., \& van der Meulen Rodgers, Y. (2021). Feminist Economic Perspectives on the COVID-19 Pandemic. Feminist Economics, 27(1-2), 1-29. doi:10.1080/13545701.2021.1876906

Khubchandani, J., Kandiah, J., \& Saiki, D. (2020). The COVID-19 Pandemic, Stress, and Eating Practices in the United States. European Journal of Investigation in Health, Psychology and Education, 10(4), 950-956. doi:10.3390/ejihpe10040067

Levine, C., Hunt, G. G., Halper, D., Hart, A. Y., Lautz, J., \& Gould, D. A. (2005). Young Adult Caregivers: A First Look at an Unstudied Population. American Journal of Public Health, 95(11), 2071-2075. doi:10.2105/ajph.2005.067702

Mattioli, A. V., Ballerini Puviani, M., Nasi, M., \& Farinetti, A. (2020). COVID-19 pandemic: the effects of quarantine on cardiovascular risk. European Journal of Clinical Nutrition, 74(6), 852-855. doi:10.1038/s41430-020-0646-Z

Matvienko-Sikar, K., Pope, J., Cremin, A., Carr, H., Leitao, S., Olander, E. K., \& Meaney, S. (2020). Differences in levels of stress, social support, health behaviours, and stress-reduction strategies for women pregnant before and during the COVID-19 pandemic, and based on phases of pandemic restrictions, in Ireland. Women and Birth, 34(5), 447-454. doi:10.1016/j.wombi.2020.10.010

Pavalko, E. K., \& Woodbury, S. (2000). Social roles as process: Caregiving careers and women's health. Journal of Health and Social Behavior, 91-105. doi.org/10.2307/2676362

Pinquart, M., \& Sörensen, S. (2003). Differences between caregivers and noncaregivers in psychological health and physical health: A meta-analysis. Psychology and Aging, 18(2), 250-267. doi:10.1037/0882-7974.18.2.250 
Prime, H., Wade, M., \& Browne, D. T. (2020). Risk and resilience in family well-being during the COVID-19 pandemic. American Psychologist, 75(5), 631-643. doi:10.1037/amp0000660

Revenson, T. A., Griva, K., Luszczynska, A., Morrison, V., Panagopoulou, E., Vilchinsky, N., \& Hagedoorn, M. (2016). Gender and caregiving: The costs of caregiving for women. In Caregiving in the illness context (pp. 48-63): Springer.

Russell, B. S., Hutchison, M., Tambling, R., Tomkunas, A. J., \& Horton, A. L. (2020). Initial Challenges of Caregiving During COVID-19: Caregiver Burden, Mental Health, and the Parent-Child Relationship. Child Psychiatry \& Human Development, 51(5), 671-682. doi:10.1007/s10578-020-01037-x

Salami, V. U., Okoduwa, S. I., Chris, A. O., Ayilara, S. I., \& Okoduwa, U. J. (2021). Opinion Review of Socioeconomic Impact of COVID-2019 on Women's Health. Frontiers in Global Women's Health, 2, 16. doi.10.3389/fgwh.2021.647421

Trujillo, M. A., Perrin, P. B., Elnasseh, A., Pierce, B. S., \& Mickens, M. (2016). Personality Traits in College Students and Caregiving for a Relative with a Chronic Health Condition. Journal of Aging Research, 2016, 3650927. doi:10.1155/2016/3650927

Wardell, J., Kempe, T., Rapinda, K. K., Single, A. N., Bilevicius, E., Frohlich, J. R., ... Keough, M. T. (2020). Drinking to cope during the COVID-19 pandemic: The role of external and internal stress-related factors in coping motive pathways to alcohol use, solitary drinking, and alcohol problems. Alcoholism: Clinical and Experimental Research, 44(10), 2073-2083.doi:10.31234/osf.io/8vfp9

Wang, C., Pan, R., Wan, X., Tan, Y., Xu, L., Ho, C. S., \& Ho, R. C. (2020). Immediate psychological responses and associated factors during the initial stage of the 2019 coronavirus disease (COVID-19) epidemic among the general population in China. International Journal of Environmental Research and Public Health, 17(5), 1729.

Werneck, A. O., Silva, D. R. da, Malta, D. C., Souza-Júnior, P. R. B. de, Azevedo, L. O., Barros, M. B. de A., \& Szwarcwald, C. L. (2020). Lifestyle behaviors changes during the COVID-19 pandemic quarantine among 6,881 Brazilian adults with depression and 35,143 without depression. Ciência \& Saúde Coletiva, 25(suppl 2), 4151-4156. doi:10.1590/1413-812320202510.2.27862020

Woskie, L., \& Wenham, C. (2021). Do Men and Women "Lockdown" Differently? Examining Panama's Covid-19 Sex-Segregated Social Distancing Policy. Feminist Economics, 27(1-2), 327-344.

Women and Caregiving: Facts and Figures. (2020, November 12). Family Caregiver Alliance. Retrieved from https://www.caregiver.org/resource/women-and-caregivingfacts-and-figures/

Zajacova, A., \& Lawrence, E. M. (2018). The Relationship Between Education and Health: Reducing Disparities Through a Contextual Approach. Annual review of public health, 39, 273-289. doi:10.1146/annurev-publhealth-031816-044628 
Author(s) will retain the copyright of their published articles agreeing that a Creative Commons Attribution 4.0 International License (CC BY 4.0) terms will be applied to their work. Under the terms of this license, no permission is required from the author(s) or publisher for members of the community to copy, distribute, transmit or adapt the article content, providing a proper, prominent and unambiguous attribution to the authors in a manner that makes clear that the materials are being reused under permission of a Creative Commons License. Views, opinions and conclusions expressed in this research article are views, opinions and conclusions of the author(s). Open Access Publishing Group and European Journal of Education Studies shall not be responsible or answerable for any loss, damage or liability caused in relation to/arising out of conflicts of interest, copyright violations and inappropriate or inaccurate use of any kind content related or integrated into the research work. All the published works are meeting the Open Access Publishing requirements and can be freely accessed, shared, modified, distributed and used in educational, commercial and non-commercial purposes under a Creative Commons Attribution 4.0 International License (CC BY 4.0). 